\title{
Defence Spending and Economic Growth: Re-examining the Issue of Causality for Pakistan and India
}

\author{
RIZWAN TAHIR
}

\section{INTRODUCTION}

What is the impact of carrying a heavy defence burden on the country's economic development and growth? Views expressed in the literature ${ }^{1}$ argue that national defence is a consumption good which reduces economic growth by reducing saving and capital investment. A number of empirical studies have investigated the possible trade-offs between defence spending and other government expenditures like health and education. Empirical evidence concerning the relationship between defence spending and economic growth for developed countries is not inconsistent with the view that defence reduced the resources available for investment and hurts economic growth. See, for example, Benoit (1973). The evidence for developing countries, however, has not been entirely consistent or conclusive. ${ }^{2}$ Benoit (1978), using data on 44 less developed countries (LDCs) for the period 1950-65, found a strong positive association between defence spending and growth of civilian output per capita. Fredericksen and Looney (1982), using data for the period 1960-78 on a large cross-section, concluded that increased defence spending assists economic growth in resource-rich countries and not in resource-constraint ones. Using a sample of 54 LDCs pertaining to the period 1965-73, Lim (1983) found that defence spending hurts economic growth. Biswas and Ram (1986) in a sample of 58 LDCs for time-periods 1960-70 and 1970-77, using conventional and augmented growth models, concluded that military expenditures neither help nor hurt economic growth to any significant extent.

Most of the studies, mentioned above, typically use Ordinary Least Square (OLS) to estimate the following growth equation:

$$
\dot{Y}=\beta_{0}+\beta_{1} X+\beta_{2} \dot{M}+\varepsilon
$$

where $\dot{Y}$ is the rate of growth of GDP, $X$ is a vector of other explanatory variables, $\dot{M}$

Rizwan Tahir is Assistant Professor at the International Institute of Islamic Economics, International Islamic University, Islamabad.

Author's Note: I am grateful to the Institute of Policy Studies (IPS), Islamabad, for making its research facilities available to me to complete this paper. I would also like to thank Mr Naveed A. Malik for his assistance in data collection.

${ }^{1}$ See, for example, Joerding (1986)

${ }^{2}$ See Chan (1985) for a review of the existing literature. 
is the rate of growth of military expenditures and $\varepsilon$ is the classical random disturbance term. The estimated parameters would be biased and inconsistent if any of the independent variables is not econometrically exogenous. Joerding (1986) raised this issue by arguing against the assumed exogeniety of military expenditures. He employed Granger causality to test for the exogeniety of defence spending in a sample of 57 LDCs for the period 1962-1977. He found that defence spending is not a strongly exogenous variable relative to economic growth, suggesting that previous studies were flawed.

LaCivita and Fredericksen (1991) pointed out that Joerding's result is based on a pooled sample, and argued that splitting a pooled sample into separate groups can lead to quite different results. They also questioned Joerding's analysis for assuming a common lag structure for all of the countries in a sample. They re-examine the defence-growth causality issue for 21 countries for the years 1952-82, including Pakistan and India, individually over time and in a pooled sample. Employing the Granger causality procedure adopted by Joerding, ${ }^{3}$ they replicated Joerding's result that growth Grangercauses defence, but not vice versa in a pooled sample. The causal relationship, however, differed from country to country with no relationship for majority of the sample including Pakistan and India. The analysis was based on an arbitrary lag structure of four years both in a pooled sample and for each individual country. They also used the Granger causality method developed by $\mathrm{Hsiao}^{4}$ (1981) on each country individually and on a pooled sample. They found that the feedback relationship exists not only for a pooled sample but also for most of the countries including Pakistan. No relationship was found for four countries in the sample including India.

Oskooee and Alse (1993) pointed out three major shortcomings associated with such time-series studies as that of LaCivita and Fredricksen (1991). First, these studies did not check for co-integrating properties of the time series involved. Since, as argued by Granger (1988), any causal inference would be invalid if the time series involved are co-integrated. Second, to avoid a spurious regression result because of non-stationarity tendencies of most economic time series, they use rates of change instead of levels. Miller (1991) argued that rates of change, which is close to the concept of firstdifferencing, filters out low-frequency (long-run) information. The co-integration technique $^{5}$ and error-correction modelling are recommended to remedy this problem. Third, these studies use annual data because of the unavailability of quarterly or monthly observations. So the lack of causation could be the result of temporal aggregation.

Whether defence spending helps economic growth is an important policy consideration for developing countries, specially for Pakistan and India; since defence expenditure of both of these countries absorbs a significant portion of their public

\footnotetext{
${ }^{3}$ They employed the procedure as described in Granger (1969).

${ }^{4} \mathrm{Hsiao}$ has developed a systematic method for choosing lag lengths for each variable in an equation. ${ }^{5}$ See, for example, Engle, Robert and Granger (1987).
} 
current expenditures. This motivated us to re-examine the issue of defence-growth causality, for Pakistan and India, by taking into consideration the above-mentioned major shortcomings of the time series studies. Although all three shortcomings are relevant for LaCivita and Fredericksen's study, we shall not consider the third shortcoming mainly because of the unavailability of quarterly or monthly data. ${ }^{6}$ The first section illustrates the methodology used in the paper. The next section reports the empirical findings; they support the earlier result of a feedback relationship between defence and growth for Pakistan. The final section presents our conclusion.

\section{METHODOLOGY}

Co-integration and error-correction modelling technique involves three main steps. Testing the relevant time series for stationarity (unit roots), testing for cointegration, and finally error-correction modelling. We shall use standard textbook ${ }^{7}$ notation to explain briefly the steps involved.

A non-stationary time $Y_{t}$ is said to be integrated of order $d,\left[Y_{t} \sim 1(d)\right]$, if it achieves stationarity after being differenced $d$ times $^{8}$. To determine the order of integration, unit root tests have been developed. The most common test is known as Dickey-Fuller $^{9}(\mathrm{DF})$ or Augmented Dickey-Fuller (ADF) ${ }^{10}$. To discuss the DF test, consider the model

$$
\begin{aligned}
& Y_{t}=\beta_{0}+\beta_{1} t+u_{t} \\
& u_{t}=\alpha u_{t-1}+\varepsilon_{t}
\end{aligned}
$$

where $\varepsilon_{t}$ is a covariance stationary process with zero mean. The reduced form for this model is

$$
Y_{t}=\gamma+\delta t+\alpha Y_{t-1}+\varepsilon_{t} \quad \ldots \quad \ldots \quad \ldots \quad \ldots
$$

where $\gamma=\beta_{0}(1-\alpha)+\beta_{1} \alpha$ and $\delta=\beta_{1}(1-\alpha)$. This equation is said to have a unit root if $\alpha=1$. The DF test is based on testing the hypothesis $\alpha=1$ in [1] under the assumption the $\varepsilon_{t}$ are white noise errors. The test statistics are:

$$
K(1)=T(\hat{\alpha}-1) \quad t(1)=\frac{\hat{\alpha}-1}{S E(\hat{\alpha})}
$$

since these statistics do not have a standard $t$ distribution, the critical values for $K(1)$ and $t$ (1) are tabulated in Fuller (1976)

${ }^{6}$ Similar constraint compelled us to focus only on Pakistan and India.

${ }^{7}$ The discussion is based on Maddala (1988) "Introduction to Time Series Analysis”.

${ }^{8}$ This definition is due to Granger (1986) and Engle and Granger (1987).

${ }^{9}$ Dickey, and Fuller (1979).

${ }^{10}$ Engle and Granger (1987) has argued that ADF test allows for dynamics in the DF regression and consequently is over-parameterised in the first order case but correctly specified in the higher order cases. 
Suppose that $Y_{t} \sim I(d)$ and $x_{t} \sim I(d)$. Then $Y_{t}$ and $X_{t}$ are said to be co-integrated if there exists a $\beta$ such that $Y_{t}-\beta x_{t}$ is $I(d-b)$ and $b>0$. Thus testing for co-integration one must make sure that both series are integrated of the same order in first step. Second step then involves estimating the following co-integration equations by Ordinary Least Squares (OLS):

$$
\begin{array}{llllll}
Y_{t}=a_{0}+b_{0} X_{t}+\mu_{t} & \ldots & \ldots & \ldots & \ldots & \ldots \\
X_{t}=a_{0}+b_{0} Y_{t}+\mu_{t}^{\prime} & \ldots & \ldots & \ldots & \ldots & \ldots
\end{array}
$$

and testing for the stationarity of the residuals from Equations 2 and 3 to make sure that $\mu_{t}$ and $\mu_{t}^{\prime} I(d-b)$, where $b>0$. Co-integration Regression Durbin-Watson statistic (CRDW), ${ }^{11}$ in addition to DF and ADF, can also be used to test the stationarity of the residuals.

If two variables are co-integrated, then the third step involves formulating the error-correction model (ECM) as follows:

$$
\begin{aligned}
& (1-L) Y_{t}=C_{0}+d_{0} \mu_{t-1}+\sum_{i=1}^{M} e_{0 i}(1-L) Y_{t-i}+\sum_{i=1}^{N} f_{0 i}(1-L) X_{t-i}+\varepsilon_{t} \quad \ldots \\
& (1-L) X_{t}=C_{1}+d_{1} \mu_{t-1}^{\prime}+\sum_{i=1}^{M} e_{1 i}(1-L) X_{t-i}+\sum_{i=1}^{N} f_{1 i}(1-L) Y_{t-i}+\varepsilon_{t}^{\prime} \quad \ldots
\end{aligned}
$$

where $L$ is the lag operator and the error correction terms (ECTs) $\mu_{t}$ and $\mu_{t}^{\prime}$ are the stationary residuals from co-integration Equations 2 and 3, respectively. According to the standard Granger causality test, $X$ is said to Granger cause $Y$ if $f_{0 i}$ 's are jointly significant. The inclusion of ECTs, however, provide additional channel through which the Granger causality could be detected. Thus, $X$ is said to Granger cause $Y$, as long as the ECT carries a significant coefficient even if $f_{0 i}$ 's are not jointly significant. ${ }^{12}$

\section{THE EMPIRICAL RESULTS}

The three steps of the co-integration technique and error-correction modelling, described above, are employed to investigate the relation between real defence spending (DFN) and real output (GDP) for Pakistan and India. We use log of these variables, such that their first differences could reflect the rate of change of each variable. The data on Pakistan's GDP and DFN for the period 1961-63 are obtained from various issues of Pakistan Economic Survey. The data on India's GDP for the period 1960-89 are taken from United Nations Statistical Yearbook and on DFN, for the same period, from the United Nations Statistical Yearbook: Asia and the Pacific.

\footnotetext{
${ }^{11}$ If residuals are non-stationary, the DW will approach zero and thus the test rejects non-co-integration.

${ }^{12}$ Granger (1988), p. 203.
} 
The results corresponding to each step of the technique are reported in Tables 1 , 2, and 3 respectively. Results reported in Table 1 show that the calculated DF/ADF (with and without trend) statistics are less than their critical values only for first differences of $\log$ GDP and $\log$ DFN for each country. This indicates that both variables are integrated of order one, i.e., 1(1). If residuals from co-integration regressions are found to be integrated of order zero, i.e., 1(0), log GDP and log DFN would be considered cointegrated. Results of four co-integration regressions, two for each country, are reported in Table 2. Along with DF/ADF tests, Co-integration Regression Durbin-Waston (CRDW) statistic and the slope coefficients of each equation are also reported in the same table. The calculated DF/ADF statistics for residuals are less than their critical values. ${ }^{13}$ This suggests that all residuals are stationary and are integrated of order zero, i.e. 1(0), which in turn implies that log GDP and log DFN series of both countries are co-integrated.

Alternative to DF/ADF tests, the CRDW statistic could also be used to determine the stationarity of residuals. For them to be stationary, the CRDW must be significantly different zero. The calculated CRDW for log GDP and log DFN of Pakistan are larger than the critical values at 5 and 10 percent levels of significance. This confirms the stationarity of residuals in the case of Pakistan. The CRDW statistic, however, does not appear to confirm the stationarity of residuals in the case of India. ${ }^{14}$

The sign of slope coefficients shows that the long-run relationship between defence spending and output is positive for each country. Therefore, increase in defence spending stimulates output, and an increase in output also stimulates defence spending. This result is consistent with the findings of earlier studies at least in the case of Pakistan.

The above analysis suggests that there exists a long-run relationship between defence spending and output in each country. But in order to determine which variable Granger causes the other and provides the short-run dynamics adjustment toward the long-run equilibrium, error-correction (EC) models were also estimated. Since EC model, as described by Equations 4 and 5, involves lag variables, one must determine the optimal number of lags for each variable. An F-test was used for this purpose to select the appropriate specification in each case. The results are reported in Table 3.

The results indicate that there exists bi-directional causality between defence spending and output for both countries. In each case, not only the lagged independent variables are jointly significant; the EC term also turns out to be significant. This significance varies from 1 percent to 10 percent level. This result is consistent with the

\footnotetext{
${ }^{13}$ With the exception of residuals from co-integration, regression for India' GDP. In this case, although the calculated DF is greater than its critical value, the calculated $\mathrm{ADF}$, however, is less than the critical value. Because ADF is preferable, we considered these residuals to be stationary.

${ }^{14}$ We considered both residuals to be stationary on the basis of the ADF test. Engle and Granger (1987) recommend the use of the ADF test owing to its higher power .
} 
Table 1

Results of DF \& ADF Tests Applied to GDP \& DFN Variables and Their First Differences

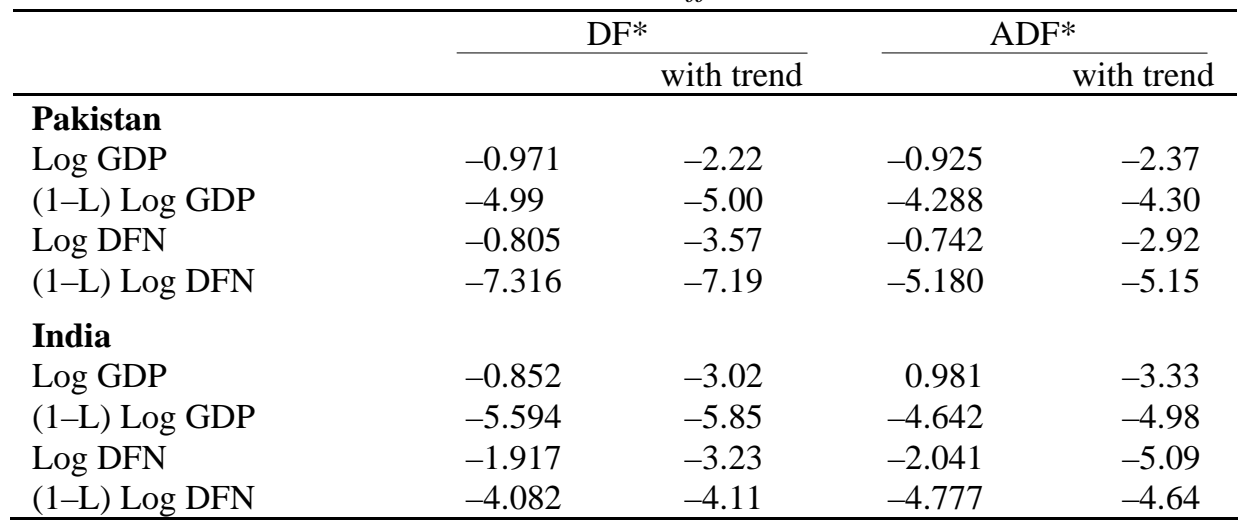

Notes: The critical value of DF/ADF statistic in the vicinity of 25 observations from Fuller's table is 3.00 without trend and -3.60 with trend at 5 percent significance level. See Fuller (1976), p. 373. *We calculated both $K(1)=T(\hat{\alpha}-1)$ and $t(1)=\frac{\hat{\alpha}-1}{S E(\hat{\alpha})}$ statistics based on Equation 1 in the text. Since we obtained similar results from both test-statistics, only $t(1)$ statistic results are reported here.

Table 2

Results of DF/ADF Tests Applied to the Residuals of Co-integration Equation

\begin{tabular}{lcccc}
\hline $\begin{array}{l}\text { Co-integration } \\
\text { Equation }\end{array}$ & Slope Coefficient & $\mathrm{CRDW}^{\mathrm{a}}$ & $\mathrm{DF}^{\mathrm{b}}$ & $\mathrm{ADF}^{\mathrm{b}}$ \\
\hline Pakistan & $\begin{array}{c}0.855^{*} \\
\text { Log GDP }=\mathrm{f}[\log \text { DFN }]\end{array}$ & 1.41 & -4.11 & -3.39 \\
& $\begin{array}{c}1.119^{*} \\
\text { Log DFN = f[Log GDP] }\end{array}$ & 1.48 & -4.21 & -3.51 \\
& $(26.36)$ & & & \\
India & $0.898^{*}$ & 0.595 & -2.82 & -3.53 \\
Log GDP = f[Log DFN] & $(12.83$ & & & \\
& $0.951^{*}$ & 0.668 & -3.73 & -3.77 \\
Log DFN = f[Log GDP] & $(12.83)$ & & & \\
\hline
\end{tabular}

${ }^{\mathrm{a}}$ The critical value of the CRDW (Co-integration Regression Durbin-Watson) statistic in the vicinity of 50 observations is 0.78 at the 5 percent level and 0.69 at the 10 percent level. These are from Engle and Yoo (1987), Table 4.

${ }^{\mathrm{b}} \mathrm{DF} / \mathrm{ADF}$ tests reported are based on Equations excluding trend.

*Significant at 1 percent level. 
Table 3

Results for Error-correction Models

\begin{tabular}{|c|c|c|c|c|}
\hline Country & $\begin{array}{l}\text { Dependent } \\
\text { Variables }\end{array}$ & $\begin{array}{l}T \text {-statistic for } \\
\text { EC-1 }\end{array}$ & $\begin{array}{l}\text { F-statistic for } \\
\sum(1-\mathrm{L}) \log \\
\text { GDP }\end{array}$ & $\begin{array}{c}\text { F-statistic for } \\
\sum(1-\mathrm{L}) \log \\
\text { DFN }\end{array}$ \\
\hline \multicolumn{5}{|l|}{ Pakistan } \\
\hline & $(1-\mathrm{L}) \log$ GDP & $2.78 * *$ & $2.61[2] * * *$ & $4.65[6]^{* *}$ \\
\hline & (1-L)log DFN & $-4.22 *$ & $32.62[5]^{*}$ & $2.74[2] * * *$ \\
\hline \multicolumn{5}{|l|}{ India } \\
\hline & $(1-\mathrm{L}) \log$ GDP & $2.24 * *$ & $0.208[1]$ & $3.07[5]^{* *}$ \\
\hline & $(1-\mathrm{L}) \log \mathrm{DFN}$ & $-1.82 * * *$ & $3.12[5]^{* *}$ & $0.53[6]$ \\
\hline
\end{tabular}

Notes: EC denotes the Error-correction term. Numbers inside the brackets are the number of lags. $*$, ** and ${ }^{* * *}$ shows significance at 1 percent, 5 percent, and 10 percent levels.

earlier finding [LaCivita and Fredericksen (1991)] of a feedback relationship between defence spending and output in the case of Pakistan. Our result in the case of India, however, does not support the result of no relationship between defence and output as established in the earlier studies.

\section{CONCLUSION}

In the past ten years, a number of studies have attempted to analyse the relationship between defence spending and economic growth in less developed countries (LDCs). The results are neither consistent nor conclusive. Two time series studies have investigated a possible causal relationship between defence spending and economic growth. After pointing out the weaknesses of these studies, we re-examined the issue of causality between defence and growth. Co-integration technique and error-correction modelling were adopted for this purpose. Our results confirm a feedback relationship, as found in the previous studies for Pakistan. The analysis also suggests a feedback relationship for India-a result which does not support the earlier finding of no relationship.

The following three favourable factors are being mentioned in the literature [Benoit (1978)], in order to justify the feedback relationship between defence and growth. First, the military expenditures help to introduce the people to modern skills and attitudes. Second, the military's capital expenditures (e.g., roads, bridges, airports) have alternative civilian values and help to strengthen the country's economic infrastructure. And third, defence spending leads to mild inflation, which in turn encourages fuller utilisation of the existing production facilities. Similar effects of defence spending also justify a feedback relationship for India and Pakistan, as obtained in this paper.

For further research, one may wish to investigate any causal relationship between 
the defence expenditures of these two neighbouring countries. Whether the decision of the Pakistani government to increase the defence budget stimulates the Indian government to enhance its defence also, or vice versa, is be worth analysing.

\section{REFERENCES}

Benoit, E. (1973) Defence and Economic Growth in Developing Countries. Boston: D. C. Heath \& Co., Lexington Books.

Benoit, E. (1978) Growth and Defence in Developing Countries. Economic Development and Cultural Change 26: 271-80.

Biswas, B., and R. Ram (1986) Military Expenditures and Economic Growth in Less Developed Countries: An Augmented Model and Further Evidence. Economic Development and Cultural Change 34: 361-72.

Chan, S. (1985) The Impact of Defence Spending on Economic Performance: A Survey of Evidence and Problems. Orbis 29: 403-34.

Dickey, D. A., and W.A. Fuller (1979) Distribution of the Estimators for Autoregressive Time Series with a Unit Root. Journal of the American Statistical Association 84: $427-31$.

Engle, R. F., and B. S. Yoo (1987) Forecasting and Testing in Co-integration Systems. Econometrica 35: 143-59.

Engle, R. F., and C. W. J. Granger (1987) Co-integration and Error Correction: Representation, Estimation, and Testing. Econometrica 55: 251-76.

Fredericksen, P. C., and R. E. Looney (1982) Defence Expenditures and Economic Growth in Developing Countries: Some Further Empirical Evidence. Journal of Economic Development 7: 113-26.

Fuller, W. A. (1976) Introduction to Statistical Time Series. New York: John Wiley and Sons.

Granger, C. W. J. (1969) Investigating Causal Relations by Econometric Models and Cross-Spectral Methods. Econometrica 37: 424-38.

Granger, C. W. J. (1986) Developments in the Study of Co-integrated Economic Variables. Oxford Bulletin of Economics and Statistics 48:3 213-28.

Granger, C. W. J. (1988) Some Recent Developments in a Concept of Causality. Journal of Monetary Economics 39: 199-211.

Hsiao, C. (1981) Autoregressive Modelling and Money-income Causality Detection. Journal of Monetary Economics 7: 85-106.

Joerding, W. (1986) Economic Growth and Defence Spending: Granger Causality. Journal of Development Economics 21: 35-40.

LaCivita, C. J., and P. C. Frederiksen (1991) Defence Spending and Economic Growth: An Alternative Approach to the Causality Issue. Journal of Development Economics 35: 117-126. 
Lim, David (1983) Another Look at Growth and Defence in Less Developed Countries. Economic Development and Cultural Change 31: 377-84.

Maddala, M. D. (1988) Introduction to Time Series Analysis.

Miller, M. S. (1991) Monetary Dynamics: An Application of Co-integration and Errorcorrection Modelling. Journal of Money, Credit and Banking 23: 2 139-54.

Oskooee, M. Bahamani, and J. Alse (1993) Export Growth and Economic Growth: An Application of Co-integration and Error-correction Modelling. The Journal of Developing Areas 27: 535-542. 